\title{
Moral problems and Countermeasures in China's Network Marketing
}

\section{Suzhen Yu, Guanghua Li, Li Wang*}

Nanchang Institute Of Science \& Technology, Jiangxi Nanchang, Chinese,330108.

Nanchang Institute Of Science \& Technology, Jiangxi Nanchang, Chinese,330108.

Jiangxi University of Traditional Chinese Medicine, Jiangxi Nanchang, Chinese,330100.

"Correspondent authors:

key words network marketing; marketing ethics; moral construction

\begin{abstract}
With the development of Internet economy, network marketing appears in front of the public as a new marketing method, but the new marketing method of network marketing often walks in the grey area of law, and produces many moral problems. In order to maintain the Internet environment, ensure a good network marketing atmosphere, and promote the development of Internet economy, we should start from multi-directional and multi-level, strengthen the construction of network marketing morality, and put an end to non-compliance with laws and regulations. First to build a perfect, orderly external environment. This requires a perfect regulation of laws and regulations. Therefore, it is necessary to amend and complete the e-commerce law as soon as possible, and amend and improve other relevant laws and regulations such as the Advertising Act. improve the supervision mechanism and industry norms. Secondly, we should construct a good internal moral environment, for enterprises to establish social marketing concept, cultivate their own moral quality, and develop a good marketing culture of enterprises.
\end{abstract}

Topic: Project-based Teaching and Practice of Network Marketing Course Based on Entrepreneurship Orientation. Item number: NCJG-17-04.

Topic: Research on the Formation Mechanism and Educational Incentive of College Students' Entrepreneurship Willingness Based on TPB Theory

\section{Moral problems in Network Marketing in China}

With the development of the Internet, the communication of information is very rapid, and the information security of network citizens has been paid special attention to. The most easy problem to touch in the process of network marketing is to invade personal privacy. According to the law of our country, every Chinese citizen has the right to privacy, the information secret that the individual has nothing to do with the public interest, and the private domain is protected by the law. No citizen may allow, others may not steal and divulge personal privacy information. In the process of network marketing, the main privacy problems that may be encountered can be divided into three aspects.

\subsection{Private collection of user information by illegal means without the knowledge of the user}

In the past traditional marketing process, the way to obtain consumer information is to do market research, the realization of this method is through the permission of consumers. But today, when the Internet goes deep into everyone's life, user information is easy to be obtained by others using network technology.

\subsection{Illegal resale of user personal information}

many of the web sites and applications now require personal information to be provided to complete the registration when the user is in use, the method obtaining the user's personal information is a reasonable range by the user's consent, provided that the website or application protects the user's personal information from being leaked, No other improper use. Some enterprises, in order to obtain the benefit of their eyes, sell the user information to other enterprise companies without 
permission, then this kind of behavior infringes the user's right to privacy and the right to know, and has caused great living interference and information security hidden trouble to the users.

\subsection{Waste information flooding}

The use of e-mail to send the information to the user is an important means of the current network marketing. But this creates a large amount of spam and information. There is no doubt that push messages and messages, which are constantly being received by the user and are not of interest, are undoubtedly a matter of vexation, disturbing the well-being of the user's life and contaminating the storage environment of the user's electronic equipment. And the quality of these e-mail content is uneven, which also gives the user the impression that the e-mail marketing is not good enough to create some misconceptions. The past is not conducive to the development of e-mail marketing. At present, the problem of spamming has become a worldwide problem The same problem.

\section{4 in online transactions, sellers and sellers are in different places in space, and payment and delivery are not uniform in time}

Consumers cannot personally inspect the goods and cannot receive them in time. The whole transaction is on a virtual platform with no guarantee. This kind of characteristic gives the network illegal element to have the opportunity to take advantage of. Network fraud has become a serious problem, which seriously damages the interests of consumers and is not conducive to the normal development of network marketing. There are several typical types of network fraud:

\section{5 false transactions to defraud consumers of their transactions}

In the network transaction, the buyer can't get the goods immediately after the payment. The illegal marketing personnel take advantage of this empty son to defraud the consumer's transaction with the false goods, often the amount of the payment is small, and the consumer can not take effective measures to recover the loss even if it is cheated.

\subsection{To be inferior, to be false.}

Because the consumer can't check the goods on the spot, the network can only see the pictures and the text introduced by the seller, but the information displayed by the sellers can be forged and beautified, which also gives the seller the opportunity to make the fake.

\section{The consequences of moral misconduct in Network Marketing}

\section{1 harm to consumers}

The immoral behavior of marketers causes great interference to consumers' life, seriously damages the economic interests of consumers, and even threatens the safety of consumers' lives.

\section{2 impact on the development of the enterprise itself}

Although the enterprise can make a profit in a short time by selling client information, fraudulent marketing and other means, it is not conducive to the reputation of the enterprise in the long run, and the bad behavior of the enterprise will be subject to the sanction of the society once it is exposed.

\subsection{Disruption of the fair competition order}

Under the normal economic order, each enterprise should be fair competition, and each enterprise can win by product and service quality. The vitality of such an enterprise is long, and the benefits obtained are legal. However, some enterprises have ignored the principle of fairness and competition, and in order to suppress other enterprises, monopolize the market, use the means of non-visible light to steal commercial secrets, low-price dumping of goods, malice and other acts. The normal market order is seriously damaged, and the normal production activities of the society are affected. 


\subsection{The credibility of the society is reduced, and the public interest of the society is damaged}

On the question of marketing ethics, he has many differences with other moral problems, and has its special situation. The enterprise marketing, there will also be a false phenomenon, make many false advertisements, so many consumers can't really get the satisfaction, the consumer is with very strong mobility, but after they are taken for, in a very short time, this message will spread among other consumers, under the help of the network, the false information is rapidly expanded in a very short time, and in the network environment, the false information is filled with a lot of false information, so that the credit of many consumers to the society and the enterprise is greatly reduced, and finally, The credibility of the whole society is declining. In order to obtain more benefits, enterprises do whatever means to make the social atmosphere worse and worse, which has caused great obstacles to the construction of socialist spirit and disrupted the social and public interests.

\section{How to solve the problem of Marketing morality in China}

With respect to the improvement of the marketing ethics, it is not a one-time job, and more is the need to insist, if not, the enterprise will be seriously affected, and it is also related to the culture and other aspects of the society, so it needs to be solved from more angles. To strengthen the management and construction of network marketing, to play a more active role under the premise of being in accordance with the law, to make the enterprises that violate the rules and break the moral bottom line, and strive for strict disposal, so that a good network marketing can be truly built.

\section{1 improvement and strengthening of the external environment}

It is necessary to do the management in the form of an association, and from the present point of view, the trade association is very common, so that many scattered information are concentrated together to form specific standards and regulations, and there is also an industry implementation rule. Therefore, with respect to a series of problems, such as the regulation of network moral marketing, the association must act as a norm and management. In order to find and focus on the behavior of the violation of the moral marketing, it is the advantage of the trade association, and it can be found more timely for some of the problems that are in violation of the morality, and can also be pre-predicted for some of the upcoming problems. The unified marketing ethics standard is formulated It is a very good link, the activity of the market is regulated under the action of the market. To actively promote, educate, and play a moral advantage.

\subsection{On the Moral Construction of Network Marketing}

Enterprises should set up correct moral concept, apply moral construction in marketing strategy, cultivate excellent corporate culture and build the core idea of enterprises.

\subsubsection{The primary goal of an enterprise is to establish the right marketing philosophy.}

In their activities, enterprises should always alert themselves, do not do whatever means for the sake of interests, have appropriate strategic ideas, under legal circumstances, can not be mercenary, can not abandon the moral bottom line; marketing activities need to meet the needs of the masses, and should be above the legal level. Only in this way can we ensure the long-term development of enterprises.

3.2.2 leaders are essential to the enterprise, so leaders should first improve their own cultural quality

As the core figure of the enterprise, we should fully realize the importance of morality. Because of the temporary interests and destroy the moral bottom line of the enterprise, this is really not conducive to the long-term development of the enterprise, the ultimate fate of the enterprise, but also can not escape. Enterprise leaders should take the lead, take the lead in creating good moral cultivation, formulate high-quality cultural ideas and establish correct values for enterprises, and improve the marketing moral behavior of enterprises through their own authority, charisma and model behavior. 


\section{Conclusion:}

In the process of development, only by paying attention to the construction of corporate ethics from the beginning, can we avoid some bad behavior activities more effectively. Therefore, enterprise leaders should attach importance to the importance of network marketing and regard it as an important part of corporate culture.

\section{References:}

[1] Research on the development of network economy in the new period[J]. Zhao Yuting. Tax. 2018 (07)

[2] Analysis of customer loyalty training under network marketing [J]. Wang Xi. Success (education) $2010(11)$

[3] Analysis of customer loyalty training under network marketing [J]. Li Pengbo, Xiao Yu. The mall is modern. 2009 (03)

[4] make the operation of network enterprises more smooth [J]. The world of software. 2000 (11)

[5] Research on Trust Mechanism of Network Enterprises [J].

[6] General plan for strong sales of network products[J]. Wang Xiaohong. Innovation and technology. 2006 (12)

[7] Wang Juntao: building an online Business Empire [J]. Zhao Xu. Chinese industry and commerce. $2000(09)$

[8] customer, partner and employee management strategy of network enterprise [J]. Ni Qingping. Economic management. 2000 (05) 